\title{
Regarding Symbolic Capital: Poetry Translators from Modern Greek into English
}

\begin{abstract}
The research object of this study is the symbolic capital of poetry translators and how it shapes and is being shaped by the current practices and self-descriptions of translators of Modern Greek poetry into English. A number of case studies indicate that people who translate poetry come from a variety of backgrounds, including those of a poet and an academic, which often do not include any formal translation training (Hofstadter 1997; Waldinger 2003; Bullock 2011; Isaxanli 2014). It also appears to be common that translators of poetry have a number of complementary roles, with that of 'poetry translator' not always central. The study draws on data consisting of Modern Greek into English poetry translators' responses to a survey, of paratexts created by Modern Greek into English translators and of ten interviews. Cultural and educational capitals are examined in their institutionalized, objectified and embodied form as bearers of symbolic capital. Three overlapping categories are explored: the translators' connection to poetry and the source culture, translator education and translator self-description. The translators' "extratextual visibility" (Koskinen 2000 as cited in Chesterman 2018: 446) is also analyzed as it forms part of the translators' embodied cultural and symbolic capital. This empirical exploration offers insights into the variety of attitudes and approaches to poetry translation; the emerging patterns map out profiles of a group of contemporary poetry translators, investigate the realities of the craft and re-position poetry translation practitioners with respect to other translation professionals.
\end{abstract}

\section{Keywords}

symbolic capital; poetry translation; Modern Greek; empirical; paratexts

\section{Introduction: Overview of research into poetry translation}

One of the first scholars in the field of Translation Studies who called for an exploration of the translatorial habitus was Simeoni, who noted that the "habitus of a translator is the elaborate result of a personalized social and cultural history" (1998: 135). More recently, translators have become the focus of Translator Studies (Chesterman 2009; Munday 2014), catalyzed by the sociological turn within the discipline. The sociology of translation regards translators as social agents who participate in the field of translation both as individuals and as members of professional networks.

Poetry translation is one of the oldest types of translation practice to be discussed from a theoretical perspective (Weissbort/Eysteinsson 2006). Poetry translators have also been prolific in their production of paratextual material in which they discuss and criticize their own translated texts as well as their translation processes (e.g. Beaugrande 1978; Felstiner 1980; Diaz-Diocaretz 1985; Gass 1999; Keeley 2000). Poetry translators have in this manner developed what Flynn calls "situated theories or models of translation" (2013: 50).

In terms of scholarly attention, poetry translators and their translatorial identity have been the object of study of a number of scholars either individually or in comparison to other translators of poetry (Ober/Ober 2004; Constantine 2011; Jacobs 2014; Munday 2016; Refsum 2017). In these studies, translators of poetry are usually named either poet-translators or poet/translators, a

\footnotetext{
* Nadia Georgiou

School of Literature and Languages

University of Surrey

k.georgiou@surrey.ac.uk
} 
choice of words which foregrounds their function as poets and does not necessarily reflect how these translators of poetry view themselves. Some attention has been paid to individual poetry translators from Modern Greek into English (Mackridge 2010; Assinder 2012), in which both descriptions are used.

The studies mentioned above usually focus on the specific practices and processes of one or two individual translators of poetry. They often offer some biographical information about the translator and then provide close readings of the source and target text and comment on the translators' choices. Such individual case studies on translators of poetry are numerous. An overview of the relevant literature reveals that the attention paid to poetry translators has been, however detailed in terms of describing the professional trajectory of individual poetry translators, largely sporadic in its employment of methods and research focus.

Recent studies offer more varied perspectives and a focus on more than one or two poetry translators. Jones $(2009,2011)$ and Flynn $(2005)$ have engaged in systematic attempts at exploring the processes and practices of poetry translators using empirical methods. Their language combinations were Dutch to English and Serbo-Croatian into English (Jones 2011) and Irish to Dutch (Flynn 2005) thus recording the workings between languages of major and lesser diffusion in the context of translation. Kenesei (2010) undertook an empirical study with 188 undergraduate students and two teachers, investigating the reception and cognition of poetry translation. Isaxanli (2014) discusses prevalent translation norms in specific periods in the Azerbaijani literary history and presents the attitudes of a number of poetry translators translating from Persian or Arabic towards their practice. An interesting project by Blakesley $(2014,2016)$, and the sole quantitative study on poetry translators so far, aims at exploring national and international trends through the translations of Italian poet-translators using statistics. The special issue of Translation and Literature (2016), edited by Blakesley and Munday, is exclusively dedicated to poetry translation and includes articles which approach poetry translating from a number of perspectives, such as translation policy, editorial choices and publishing.

As indicated by the overview presented above, there is a proliferation of information generated by poetry translators and a large amount of scholarly research on individual poetry translators as well as comparative case studies but very few systematic, methodical attempts at exploring larger groups of poetry translators categorized by language combination, time period and so on. Additionally, the emphasis has been largely on the textual characteristics of the linguistic transfer and the limitations of the poetry translator's renderings. The biographical aspect and its connection to the poetry translators' professional trajectories have been much less explored. A forthcoming publication exploring the sociology of poetry translation edited by Blakesley (2018) is a step in that direction.

This paper offers a systematic study of poetry translators from Modern Greek into English with a particular emphasis on their symbolic capital. Symbolic capital refers to a particular type of 'credit' (Bourdieu 1993: 75) or resource in the form of prestige, power or authority which endows individuals with the skills and abilities to act within specific contexts. In the present study, symbolic capital is explored with the aid of paratextual material created by poetry translators, poetry translators' responses to a survey $(\mathrm{n}=20)$ and information from interviews conducted with ten poetry translators.

In the following section I will first provide an overview of relevant literature which engages with the concepts of symbolic capital and habitus and then discuss these constitutive parts of symbolic capital with respect to the data on poetry translators from Modern Greek into English.

\section{Operationalizing capital in Translation Studies}

Cultural capital is linked to the translatorial habitus (Simeoni 1998), which is the embodiment and expression of the translators' personal and professional past and the way in which they internalize culture. The concept of symbolic capital comes from Bourdieu, who extends the concept 
of capital from its economic meaning to include nonmaterial items, such as race, ethnicity, or sex. Bourdieu argues that "all other types of capital ... are transformed, disguised forms of economic capital" (1990: 230). Swartz (1997: 80) remarks on the interconnection of economic and cultural capital that "it is after all economic capital that makes possible the investment in cultural capital by making possible the investment of time needed to accumulate cultural capital".

Symbolic and cultural capitals are often used interchangeably. The sociologist Beverley Skeggs, however, observes that any type of capital may acquire a symbolic form if it is perceived and recognized as legitimate, as in approved by authority. This legitimation is the "key mechanism in the conversion to power" (Skeggs 2015: 17). Swartz (1997: 43) notes that

activities and resources gain in symbolic power, or legitimacy, to the extent that they become separated from underlying material interests [...] Individuals and groups who are able to benefit from the transformation of self-interest into disinterest obtain what Bourdieu calls a symbolic capital.

This paper discusses the cultural and educational capital (Bourdieu 1984) of poetry translators from Modern Greek into English in their legitimized forms which carry symbolic meaning and invest the translators with symbolic capital.

With regard to cultural capital Swartz (1997: 42-43) observes that

Bourdieu's concept of cultural capital covers a wide variety of resources, such as verbal facility, general cultural awareness, aesthetic preferences, scientific knowledge, and educational credentials. His point is to suggest that culture (in the broadest sense of the term) can become a power source.

Educational capital, in turn, is the product of the "combined effects of cultural transmission by the family and cultural transmission by the school" (1984: 23). The distinction between cultural and educational capital is useful for the purposes of empirical study; the concepts frequently overlap however, since cultural capital includes educational credentials and educational capital is produced by cultural transmission, according to the above definitions.

Symbolic capital may become 'embodied', meaning it may be manifest in our behaviour and attitudes as part of our habitus (Bourdieu 1997: 41). Symbolic capital may also be objectified, meaning it may take the form of artefacts owned by the translator, such as books, or of activities conducted in the real world, such as participation in public events, as is discussed further on in this paper.

The self-description of the translator, whether the translator thinks of themselves as predominantly an academic, a scholar, a writer, an artist and so on, is closely linked to translators' cultural and educational capitals. In a discussion of habitus as a conceptual tool, Sela-Sheffy notes that "translators $[\ldots]$ are disposed to certain ways of doing things that suit their sense of "who they are and where they belong"' (2014: 45).

Sela-Sheffy's research $(2008,2016)$ offers interesting insights on the selfrepresentations of Israeli literary translators in the written media. Some of the common characteristics among the Israeli translators in this study are the freedom in selecting the materials to translate advocated by a number of translators (2008: 616). This demonstrates the translators' agency and is related to professional autonomy, defined by Ruokonen (2016: 190) as "[the] power to turn down unsatisfactory commissions and to control their [the translators'] work conditions". Such freedom to select what to translate is a manifestation of the translators' acquired symbolic capital. Another significant characteristic observed in Sela-Sheffy's study is the importance of the translator's personality. Emphasis is laid on the translators' high levels of education and their exposure to foreign languages from an early age (2008: 618), which are both indicators of acquired institutionalized and embodied educational capital which may, in turn, be transformed into its symbolic form. These two latter points will be further addressed below and in the discussion section of this article.

Symbolic capital is often transferred between related fields of cultural production, such as when a poet also translates, for instance, or when a translator's primary profession is that of an academic. Sela-Sheffy observes that "while some of them [the translators] have taken translation as their major career on which they depended for livelihood, others' reputation stemmed also from 
other careers, mainly as poets, critics, literary editors, or academics" (2008: 611). Other studies on the state of literary translation as a profession also suggest that literary translation is frequently undertaken as a secondary activity by a number of literary translators (de Jong 1999; Gouadec 2010; Wright 2016).

The complementary nature of the activity for a large number of literary translators has been documented in case studies representing varied geographical and cultural contexts and spanning several centuries. Gouanvic (2005), for instance, discusses the case of two $20^{\text {th }}$ century literary translators from French into English whose translation activities come second after their writerly work (as novelists and essayists). The Habsburg Monarchy translators in Wolf's study (2013) wore many hats, including those of teacher and newspaper columnists or commentator on cultural affairs. Wolf (2013: 516) states that "many translators operating in the newly established field brought their professional experience - often combined with symbolic capital - acquired in other fields". These findings are echoed in Sapiro (2013) who remarks that literary translators' "access to translation is based on linguistic skills and cultural capital, especially literary capital" (2013: 66). Among the main activities practiced by the $20^{\text {th }}$ century literary translators from Hebrew into French in Sapiro's study there was that of librarianship at the French National Library. Similar is the case of the translators of James Joyce's Ulysses into Polish, Russian and Czech in the 1970s (Tall 1990). Their struggle to finance the translation of such a demanding work of literature is evident in their correspondence; the Russian translator, who was also a prose writer, had no contract with the publishing house and had to subsidize the translation by lecturing and editing; the Polish translator was a screenwriter and prose writer.

The embodied and objectified forms of cultural and educational capital become manifest in the translators' personal literary tastes when choosing what to translate as well as in their personal interest in promoting a genre (Gouanvic 2005; Sela-Sheffy 2008). These forms of capital, in turn, shape the translatorial habitus. Voinova/Shlesinger (2013) have identified some of the characteristics which describe literary translators and compose their translatorial habitus. These include extensive academic background, or forms of institutionalized educational capital (2013: 43), identifying as artists and/or intellectuals and being artists in their own right (2013: 48), enjoying leisure times and having areas of interest closely bound up with their professional lives (2013:41) as well as a love of reading and/or literature (Voinova/Shlesinger 2013: 42). Love of literature, in the case of the translators Gouanvic presents in his study (2014), takes the form of striving to meet interesting authors from the source culture and engaging in literary activities, such as when a translator hosted literary evenings at his house (2014: 33), which are both examples of embodied cultural capital. Love of literature combined with enthusiasm also resulted for the translators in Gouanvic's study in translating a piece of work without having a commission for it or a specific outcome in mind (2014: 34). This is a characteristic shared by the Joyce translators mentioned above in the study by Tall (1990).

Gouanvic notes the characteristic of professional heredity which is passed on from generation to generation (2014: 32). Skeggs (2015: 24) also highlights the importance of inheritance, which is passed on from parents to children in its economic or symbolic form. Skeggs observes that "inheritance is significant to an understanding of social reproduction, class and power". Vorderobermeier (2014: 154) also observes, in respect with the formation of translatorial habitus, that

\footnotetext{
the transformation into a specific habitus might reach back to earliest childhood and even to a time before the person in question was born. This is notably the case with regard to the aspirations of parents or of an entire 'dynasty', e.g. of artists, scholars etc.
}

Lastly, an aspect of symbolic capital which is considered fundamental in most fields of translation practice is the translator's bilingualism and/or multilingualism. Language acquisition and use is a constitutive element which forms part of a translator's educational and cultural capitals. It is indeed mentioned by all the scholars cited above in their individual studies of the habitus of literary translators. Heino (2017) observes that "learning a language and adopting a culture that goes with it can also be understood as embodiment of cultural capital" (2017: 57). Bilingualism can be 
achieved in a number of ways: by being born into a bilingual family, living in a diglossic society or being educated in a language other than the mother tongue (Meylaerts 2010), by immigration or an inborn talent and effortlessness in language acquisition (Voinova/Shlesinger 2013).

Heino (2017) interestingly observes that in her survey with 87 Finnish literary translators $95 \%$ stated they have a monolingual Finnish childhood and only 5\% had a bilingual background. Heino notes that the accumulated cultural capital of a second language and knowledge of other cultures is a skill which for the majority of these translators has required "formal education and conscious study" (2017: 57) as well as a degree of motivation and determination. On the whole, the studies by Meylaerts (2010), Voinova and Shlesinger (2013) and Heino (2017) thus all highlight the strong presence of educational capital, institutionalized or not. This extensive investment in educational capital is further discussed with respect to translators of Modern Greek into English.

Cultural capital can also acquire other forms, which is in fact a reminder of the question regarding the ontology of literary translation as a field, an issue other scholars have also noted (Gouanvic 2005; Meylaerts 2013). One of the peculiarities of poetry translating is the existence of agents translating from languages they do not read, via indirect translation from other languages or by using literal word-for-word translations made by others. Ezra Pound is among the most prominent examples with his adapted versions of Chinese poetry (Wang 1965). Ted Hughes's translations of the Hungarian poet János Pilinszky are another example (Weissbort 1989; Bergin 2013).

In the corpus of Modern Greek into English poetry translators there are at least two such cases. The first case is that of Rika Lesser, a poet and translator mainly from German and Swedish into English, who worked closely with co-translator Cecilie Inglessis Margellos, acknowledged on the cover, whose mother tongue is Greek (Dimoula 2012). The second case is that of David Harsent and his versions of Yannis Ritsos' poems (Harsent 2012). The poems were translated from the Greek by two native speakers; this literal rendering was then reworked in English by Harsent. Lack of source language knowledge is one issue. What is of equal interest is that Lesser and Harsent were motivated to translate Greek poets' works despite not knowing the language. This suggests that, under cultural and/or educational capital, the overall category of 'relationship to source culture' may subsume not only the category of bilingualism/biculturalism but also other categories, such as 'motivation to translate from a specific language' or 'the work of a particular poet' and so on.

To summarize previous research, the cultural and educational capitals of literary translators are embodied and objectified in various overlapping ways: in the view of literary translation as a secondary activity, the practitioner's self-description (Poet? Translator? Poetry translator? Literary translator?), being artists in their own right, a love of reading and/or literature, enjoying leisure times and having areas of interest closely bound up with professional lives and engaging in literary activities. Finally, professional heredity, which is passed on from generation to generation, translating a piece of work without having a commission for it or a specific outcome in mind, the translators' relationship to the source culture and their language skills are equally important attributes.

In the analysis, these characteristics will be mapped on the findings from the responses to the questionnaire, the paratexts and the interviews of poetry translators from Modern Greek into English, which expand and enrich the themes listed above. However, before moving on to the results a presentation of the research methods and the materials discussed is in order.

\section{Methods and material}

The present study relies on three different types of material to explore the cultural and educational capital of poetry translators. In chronological order, firstly, I collected paratextual material created by Modern Greek into English poetry translators or written about them and their work; afterwards, I conducted an online survey and individual interviews with ten translators. Since the main focus of this paper, however, is on the survey data I will present the responses to the online 
survey first, the paratextual material second and the interviews with ten poetry translators last. In order to preserve the participants' anonymity, I will not comment on whether any of the paratexts have been produced by any of the participants or whether any of the interviewees also participated in the survey.

A tentative calculation of the total population of Modern Greek into English poetry translators currently active brings the number to 151 individuals. The translators were located via bibliographic searches. I started by accessing the online catalogue of the British Library. The online catalogue of King's College Library was also consulted, as I know they have a significant collection of resources regarding translated Modern Greek poetry. I searched the catalogues using the keywords 'Modern Greek poetry' in the first instance. After a few results came up, I noted the names of the translators and searched by translator's name as well. I also searched by poet's name, specifically using the names of well-known Modern Greek poets who I was aware that they have been translated into English (namely, Yorgos Seferis, Odysseas Elytis, Yannis Ritsos, Kiki Dimoula, C.P. Cavafy).

With the number of currently active poetry translators in mind, the number of translators $(n=51)$ I managed to contact exceeds $30 \%$ of the population. Participant recruitment can be particularly challenging and even more so when the population studied is narrowed down by the criteria of genre and language combination. At the current stage of this ongoing project, I have collected 20 responses to the survey. I have also received responses from ten translators regretting their inability to complete the questionnaire.

While the sample of 20 responses acquired cannot be considered representative of all poetry translators currently practicing, the findings, especially in conjunction with the information from the paratexts and the interviews, offer interesting and important insights into the translatorial habitus and the practices of poetry translators for this language combination. Juxtaposed with the information from individual translators' reports and the largely sporadic scholarly research on poetry translators, the information provided by these twenty respondents complements and enhances our current understanding of the act of poetry translating and of the symbolic capital of poetry translators.

Questionnaire surveys have been used in Translation Studies by a number of researchers, usually in conjunction with interviews, as I intend to do (Flynn 2005; Jones 2011). The survey presented in this paper explores some of the key themes discussed in Section 2 regarding the cultural and educational capital of poetry translators from Modern Greek into English. These include questions that elicit information about the translators' education and training, the role of the translation practice in the translators' professional lives, their relationship to reading and literature, the types and degree of engagement in literary/translational activities and their relationship to the source culture. Finally, there are questions exploring the translators' self-description and the public visibility of the translators and their work.

With regard to the paratextual materials used, paratexts are generally described as texts which extend and complement the main text (Genette 1997). Sometimes they accompany the main text, appearing in the same bound volume, and these are called peritexts; at other times the paratexts appear in external sources but maintain a link to the main text, as in the case of an interview with the author of a book, in which case they are referred to as epitexts.

In Translation Studies paratexts have been used, among other things, for the study of individual cases of translators (Hermans 2014, Meylaerts 2013, Gouanvic 2014). Paratexts often express the point of view of the writer (in this case the translator), advocate specific agendas and are heavily influenced by the cultural norms they purport to expose. As such, they may be viewed as a valuable source of information, which complements and advances our understanding of symbolic capital.

The paratexts used in this study cover a period spanning more than 25 years (1990-2016) and include interviews, acknowledgements and dedications written by or about poetry translators 
from Modern Greek into English who are currently active. Table 1 below lists the paratexts included in this study.

\begin{tabular}{|l|l|l|l|}
\hline Title/type of paratext & Translator name & Year & Pages \\
\hline $\begin{array}{l}\text { Dedication in book, } \\
\text { Acknowledgements }\end{array}$ & Alice Barnstone & 2006 & $\begin{array}{l}\text { vi, vi, xxv- } \\
\text { xxvi }\end{array}$ \\
\hline $\begin{array}{l}\text { Under Greek Light/ Online } \\
\text { Interview }\end{array}$ & Richard Berengarten & 2013 & - \\
\hline Acknowledgements in book & Rachel Hadas & 1994 & vii-viii \\
\hline $\begin{array}{l}\text { An interview with Edmund } \\
\text { Keeley/Online interview }\end{array}$ & Edmund Keeley & 2001 & - \\
\hline Dedication in book & Edmund Keeley & 1977 & Vi \\
\hline Acknowledgments in book & $\begin{array}{l}\text { William W. Reader and } \\
\text { Keith Taylor }\end{array}$ & 2006 & ix-xi \\
\hline
\end{tabular}

Table 1. Paratexts used in the current study

In the analysis, the paratexts were combed for passages which are indicative of the cultural and educational capital of poetry translators from Modern Greek into English. As discussed in Section 2, cultural and educational capital were approached through the key themes of the educational background of the poetry translators and elements of the hereditary nature of their vocation, via teachers of family members. Finally, instances of the translators' self-description were another key theme used in the study of paratextual material.

Finally, I also conducted semi-structured interviews with ten poetry translators. Several of the poetry translators currently live in the UK, a few are in Greece and a few others in the USA. For this reason, five interviews were conducted in person, three were conducted via Skype and two took the form of written questions which were sent to the poetry translators via email and to which they also responded in writing. The information gathered in interviews with participants is all anonymized. Eight of the interviews were conducted in English and two in Greek. The interview with the first participant (hereafter mentioned as P0) was conducted as a pilot study.

Sapiro notes that "interviews provide rich qualitative data for reconstructing translators' social trajectories, their representations of their activity as translators and the role that their translation activity plays in building their identity" (2013: 63). The translators were asked specific questions that aimed at exploring their educational and cultural capital as well as their self-description.

In the following section the combined information from the survey, the paratexts and the interviews is analyzed and discussed with respect to the cultural and education capital of poetry translators from Modern Greek into English. The formation and use made of the poetry translators' cultural and educational capital is explored through the sub-categories of the translators' connection to poetry and the source culture, education, self-description and visibility.

\section{Results}

What follows is a presentation and discussion of the questionnaire data, complemented by information retrieved from the paratexts and interviews conducted with poetry translators from Modern Greek into English. The information elicited from the questionnaire aims at a broad canvassing of the poetry translators' profile with the gradual exploration of their cultural capital in mind.

The survey begins with general background questions, such as age, gender, country of origin and country of current residence, education, place(s) of education and affiliation to university. On the question of gender, out of the 151 names collected for this project most poetry translators are male (100 out of 151). Out of the 57 translators contacted 26 are female and 31 are male. Out of 
the 20 translators who completed the questionnaire 7 are male and 10 female (three respondents chose not to reply to the question about their gender). Interestingly, the questionnaire sample is mainly comprised of female translators, which makes it unrepresentative of the publishing situation on the level of gender representation. Heino (2017: 56) also observes the predominance of female respondents in her survey (sixty-seven out of eighty-seven, i.e. $77 \%$ of the sample).

The respondents' ages vary from 35 to 74 with an average age of over 50 . Seven of the respondents are over the average retirement age (six respondents chose the option ' 65 to 74 years old' and one ' 75 or older'). This is similar to the findings by Heino (2017), who discovered that Finnish literary translators seem to work beyond the retirement age. I return to possible reasons for this below in connection with the translators' motivation to translate from Modern Greek.

\subsection{Connection to poetry and source culture}

The poetry translators' connection to the source culture is a point of significance in terms of their cultural and educational capital. These connections are to some extent reflected in Table 2, which presents the responses given by the participants to the question 'How did you learn Modern Greek?' The participants could choose more than one response.

\begin{tabular}{|l|c|}
\hline Options & Number of responses \\
\hline Self-taught & $\mathbf{6}$ \\
\hline Mother tongue & $\mathbf{6}$ \\
\hline University & $\mathbf{4}$ \\
\hline Bilingual & $\mathbf{2}$ \\
\hline Living in Greece & $\mathbf{6}$ \\
\hline Immersion & $\mathbf{1}$ \\
\hline I don't read Modern Greek & $\mathbf{2}$ \\
\hline No response & $\mathbf{1}$ \\
\hline
\end{tabular}

Table 2. Responses to the question 'How did you learn Modern Greek?'

Two of the respondents who replied that they are self-taught learners of Modern Greek also studied Classics; one of the respondents added the two categories of University and Immersion in their response. It appears that the leap from Ancient Greek to Modern Greek does still happen on occasion for some translators. Table 2 also illustrates the cultural capital, embodied and objectified, by the translators' residence in Greece (six out of twenty). These are not the same six translators who chose Greek as their mother tongue. Equally, one respondent chose 'Immersion' into the Greek culture and literature as a response.

The six responses 'Self-taught' reflect the degree of motivation and involvement in the learning of Modern Greek similar to that observed by Heino (2017: 57) among Finnish translators. These responses in combination with four respondents stating they learned the language at university form two types of educational capital: informal capital and institutionalized capital. Voinova and Shlesinger note that for many translators in their corpus "translational skills are acquired through experience" (2013: 43). In my data, there were only two bilingual respondents and the following interview segments reflect the poetry translators' sincere and life-long investment in learning the Greek language:

$\mathrm{P} 0^{1}$ : I spent enough time in Greece to feel an interest in modern literature

P5: I set a goal of becoming fluent in Greek when I was young

1 The participants will be referred to as P0-P9 (Participant 0, who is the pilot study conducted, to Participant 9). 
P8: I had tremendous motivation when I fell in love with Greece to know the language and to be able to read

The translators' paratexts also include multiple references to their initial contact with the Greek language and culture, as well as to their teachers and the role of their family in developing a connection with the Greek language and culture. Alice Barnstone, for example, is the daughter of Elli Tzalopoulou-Barnstone, who is of Greek origin, and Willis Barnstone, famous poet, translator and comparatist who taught in Greece in the late 1940s and has also translated Greek lyrical poetry and the poetry of Sappho, P. Neruda and R.M. Rilke among others. In her acknowledgements in her volume of collected poems by C. P. Cavafy, Alice Barnstone thanks her mother for her "generosity and determination to make her American children Greek" (2006: xxvi) and dedicates the collected poems to her mother who was "like Cavafy an exile from Constantinople" and to her father, "the first to share with me his love of Cavafy" (2006: vi). Barnstone's case illustrates Gouanvic's notion of professional heredity which is passed on from generation to generation (2014: 32) as well as the role of family in inspiring and cultivating love of poetry.

In a similar vein, Rachel Hadas notes in her acknowledgements the role of her mother who helped her "understand the intricacies of Latin poetry and to love all poetry" and who was "the first person I ever knew who embodied a passion for literature" (1994: vii). Vardoulakis (2001) writes about Keeley, in an interview the translator gave for the academic journal Colloquy, "the passion of Edmund Keeley's psyche is undivided: he is a lover of literature, to which he has devoted his life" (2001: 2, emphasis in the original).

The connection to the source culture and the role of the family can provide specific educational and cultural capital which facilitates the formation of a translatorial habitus. This is illustrated by Hadas, who in her acknowledgements notes her gratitude to her maternal grandfather whose translations convinced her that "the love of translating must be an inherited trait" (1994: vii). Her own volume of poetry translations is dedicated to her mother, her maternal grandfather and her father. Hadas's father was the famous classical scholar and translator Moses Hadas. In a personal essay entitled "Talking to my father", Hadas emphasizes her father's multi-culturalism and links it to his own translations of Ancient Greek and Latin (2015: 30-31).

Traces of the educational capital are also apparent in the interviewees' comments about their familial environment and the role it played in their further intellectual development:

P5: I always loved language and I mean I had an interest in Greek mythology and ancient architecture ancient Rome when I was a child

P8: I'd been brought up on a lot of poetry by my mother who taught English

P9: My parents loved great literature and read it to their kids.

Voinova and Shlesinger also recognize this exposure to literature/art as children, with a number of translators stressing "the advantages of a family that had a marked interest in literature, languages, art and culture" (2013: 36) as a key aspect of the literary translator's professional habitus.

The poetry translators' love of poetry and reading is also demonstrated in Figure 1 below, illustrating the reasons respondents gave for reading Modern Greek poetry. 


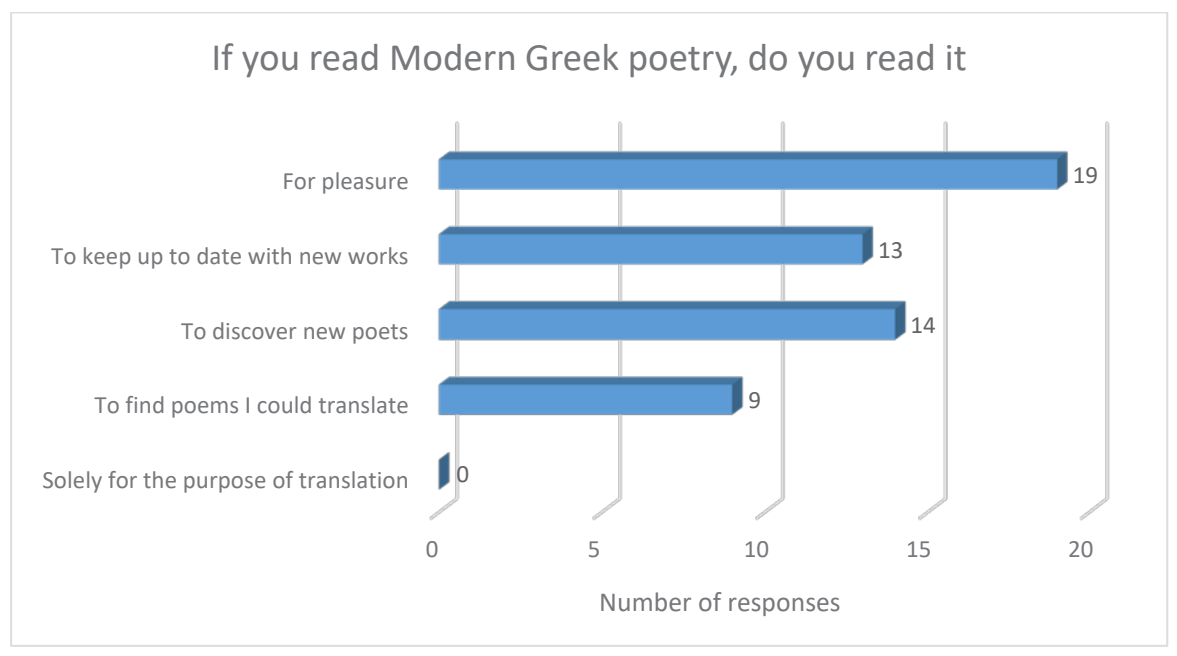

Figure 1. Reasons for reading Modern Greek poetry

Nineteen out of twenty responded that they read Modern Greek poetry for pleasure. For four respondents this was their sole response. In addition, all twenty respondents stated they read poetry originally written in English and sixteen respondents said that they read poetry in languages other than Modern Greek and English. It is significant to add that none one of the respondents selected the option of reading Modern Greek poetry solely for the purposes of translation. This is an additional manifestation of the embodied cultural capital accumulated by the poetry translators. The love of literature is probably also accompanied by experiencing literary translation as a "calling and a passion", similarly to the Finnish literary translators studied by Heino (2017: 56). This may explain why so many of both Heino's and my respondents have continued to work beyond the average retirement age. The view of translation as a calling and a passion further reflects the embodied cultural capital accumulated by the translators.

Additionally, fourteen out of twenty respondents state that another reason to read Modern Greek poetry is in order to discover new poets. This response highlights the continuing involvement of poetry translators with the source literature. The response 'To keep up to date with new works' (thirteen out of twenty respondents) captures another aspect of the translators' ongoing engagement with the evolution of the source literature as it suggests that the translators actively monitor the publishing activity of poets they already know and are looking out for potentially interesting new poetic voices.

This activity of monitoring the poetic output of Greek poets' work is inextricably linked to the option 'To find poems I could translate' (chosen by nine out of twenty respondents). It is in this response that the literary/poetic habitus morphs into the translatorial habitus, as the roles of reader of poems and writer/translator of poems overlap. The translators' investment in the role of poetry translators becomes manifest here, as does their commitment to poetic translating and their pleasure in the entire process of transforming a Greek poem into one in English.

This passion for literature and poetry, which includes Modern Greek poetry but is not limited to it, is also manifest in the some of the comments the poetry translators made in the interviews.

P8: when I think about the sort of poets that I have sitting on my desk it's so often Greeks it's so often
Cavafy and Kavvadias who's a great love of mine and also Szymborska you know I don't speak Polish
but I love her poetry so [...] I certainly thrive [laughs] thrive on great voices and I like to have them
around me I always have a shelf of really wonderful poets I admire of course Shakespeare as well or
the Bible you know this great English poetic tradition

The translators' connection to poetry as a genre is highlighted again in this comment in which three different literary traditions, separated by geography and time, are linked. This knowledge demonstrates how cultural and educational capital is embodied by the translators; an interesting 
manifestation of its objectified form is also apparent in the presence of the actual books of poetry which sit on P8's desk and on their shelves. The bond to the source culture, through their relationship to the Greek language and literature, is also demonstrated in this section, highlighting one more aspect that makes up the translatorial habitus.

In the following section, the manifestation of educational capital in the poetry translators' profiles is discussed.

\subsection{Formal education}

Educational capital is the other significant sub-category of symbolic capital being discussed. Aspects of educational capital in terms of "cultural transmission by family" (Bourdieu 1984: 23) were already discussed in the previous section, so here the focus is on more formal aspects of education.

The respondents to the questionnaire have all received high level formal education, with fourteen of them having been awarded a PhD and six an MA. The institutions in which the respondents earned their qualifications are located either in Greece, the USA or the United Kingdom.

The subjects studied are presented in Figure 2 below. They include the Classics with six responses and Literature with nine. One respondent has had formal training in translation and five have formal training in creative writing, as depicted in Figure 2. The predominance of Literature and the Classics, followed by Creative writing, suggests that the institutionalized educational capital accumulated by these poetry translators positions them primarily as literary theorists, critics and writers and emphasizes the complementarity of their translatorial activity.

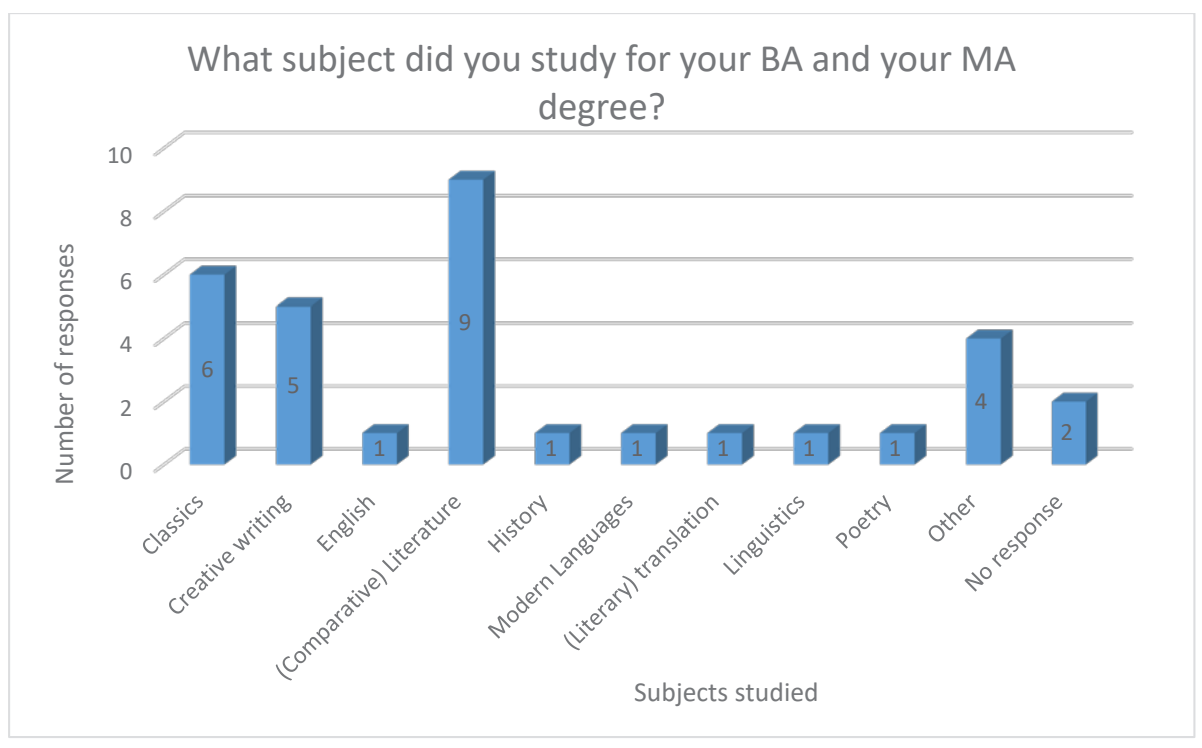

Figure 2. Subjects studied by the respondents

The respondents' choices of subjects further illustrates a love of literature, languages and writing, also noted as an important constituent part of the literary translators' cultural capital, as seen in Section 2 and manifested in the respondents' reasons for reading Modern Greek poetry discussed in the previous section.

Symbolic capital in the form of educational capital is also recorded in some paratexts. Teachers often have a largely influential role to play in shaping a potential translatorial habitus, as witnessed by the dedication in Keeley's study on Cavafy (1977) which reads "For Constantine Trypanis, who first encouraged me to read Cavafy during Michaelmas term, 1950" (1977: v). Constantine Trypanis was a poet and classical scholar who translated from the Ancient Greek and taught at Oxford. He was the translator of the very popular The Penguin Book of Greek Verse (1971). In 
a similar vein, Taylor and Reader acknowledge their debt to their "various Greek teachers" located in Greece, Cyprus and the USA "who have been involved in an ongoing conversation about Karyotakis" (2006: x).

The accumulation of the appropriate educational capital, which influences the translator's motivation, becomes equally manifest in the interviews, as two of the participants comment on the role of their teachers:

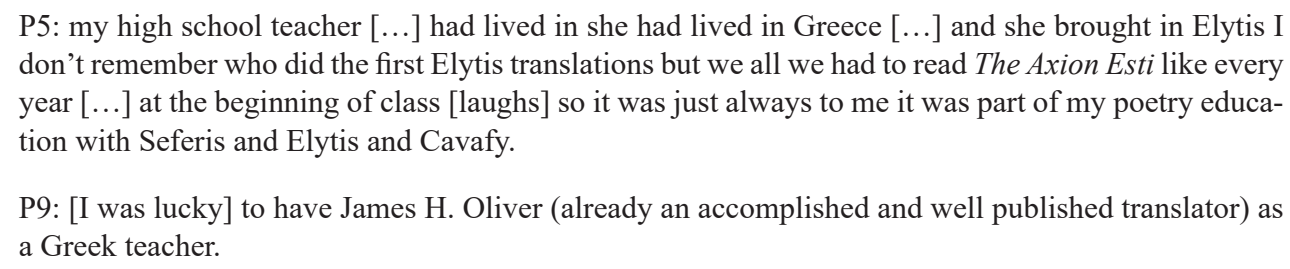

In the second example, the dual role of language teacher and translator performed by James $\mathrm{H}$. Oliver may be said to have exercised a double effect on P9 and their educational capital. What is also manifested here are two instances of the transmission of the love for a language via its literature by a teacher to their students. This is another example of the interlinked natures of the cultural and education capitals and their acquisition by the translators.

\subsection{Self-description}

This section of how poetry translators acquire and make use of their cultural and educational capital within their professional setting explores the concept of self-description, briefly presented in Section 2. Self-description expresses the embodied and internalized dispositions of the poetry translators with respect to their own sense of their positioning within the literary and translational field of production. It is therefore a significant indicator of their established internalized hierarchies of the two components of their expertise: poetry and translation.

Five categories were given in the questionnaire regarding self-description (Poetry translator, literary translator, scholar who also translates, poet who also translates and scholar/poet who also translates). For this question the respondents were free to choose one or several self-descriptions or add a completely different self-description in the blank space entitled 'Other'. Three categories were suggested by the respondents (A writer who also translates, A literary translator and a scholar, A scholar/literary translator who also writes poetry). Sixteen respondents opted for only one self-description, while two respondents chose all offered definitions. The self-definition 'a poetry translator' was chosen by both respondents in conjunction with other definitions (a literary translator, a scholar who also translates, a poet who also translates). 


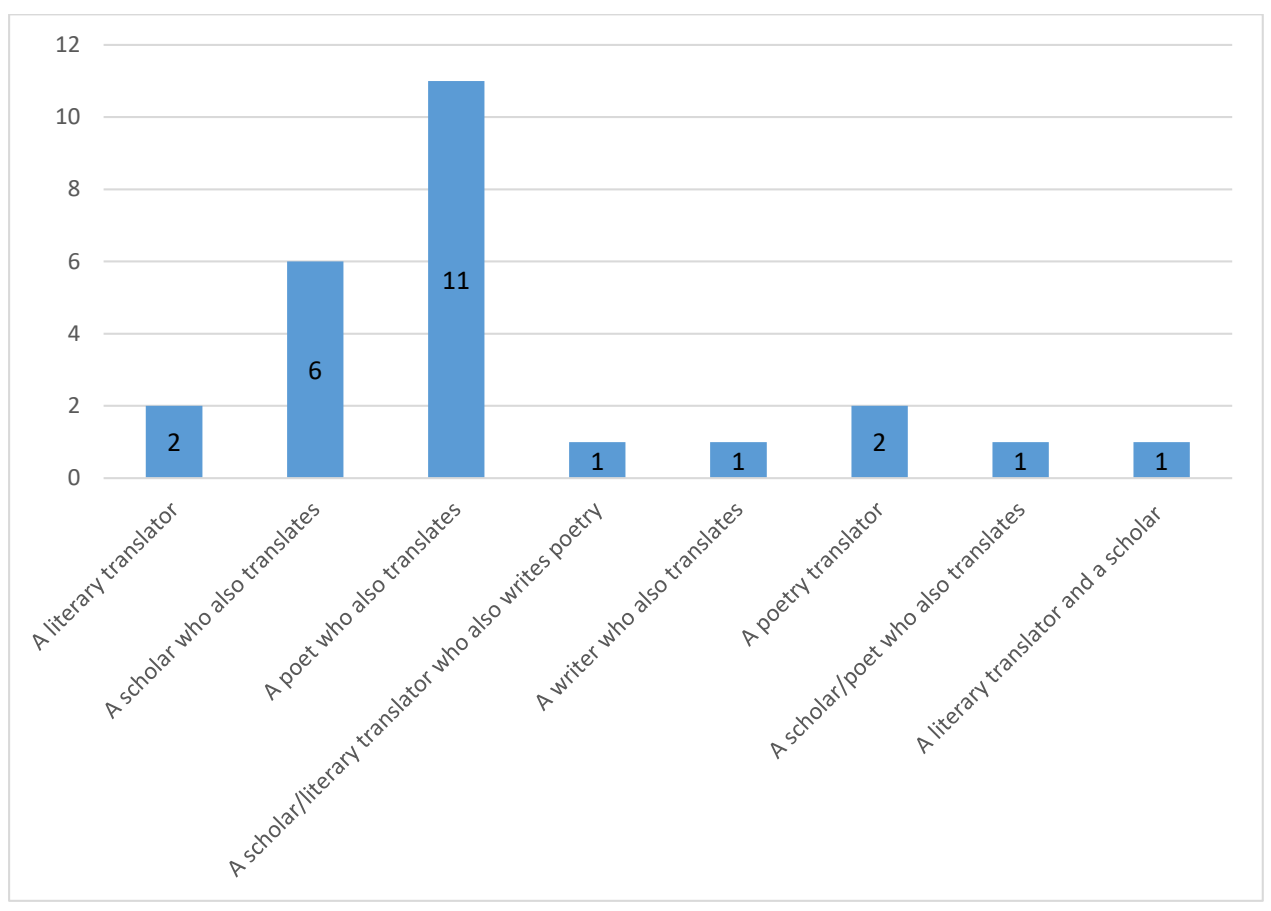

Figure 3. Self-descriptions of the survey respondents

The respondents' educational backgrounds and these self-descriptions place them within the literary field much more squarely than within the field of translation, bringing once more to the fore the issue of literary translation being a secondary or complementary activity, as mentioned in Section 2. Further research is needed on the inculcating agency that brings about such durable transformations in an individual and creates habitus and whether it would be fair to assume that the literary field is a far more powerful inculcating agency, at least in the case of the Modern into English poetry translators studied, than the translation field. These self-descriptions seem to support this reading of the data, particularly if they are considered along with the fact that sixteen out of twenty respondents said they currently write their own poetry apart from the poetry they translate. These responses add to the already existing evidence of a large number of literary translators being also writers of their own poetry/prose. This is an approach that Scott, a poetry translator and Translation scholar, advocates when he urges students of literary translation to view themselves as "translating writers" (2012: 180).

\subsection{Visibility}

On the subject of the poetry translators' visibility as practitioners, the responses to the questionnaire yielded some interesting findings. The environments in which poetry translators discuss their role as translators are found largely within academia (classroom and conferences). The prospective audience becomes broader and the respondent's "extratextual visibility" (Koskinen 2000 as cited in Chesterman 2018: 446) increases with the discussion of their role in poetry readings, festivals and writing groups. This increased visibility of literary translators is also reflected in Wright who lists the translators' involvement in "readings, panel discussions and other events as literary experts" (2016: 13) and as promoters of translated literature. An attempt at a wider spectatorship is also achieved with the discussion of translation in TV and/or radio programs (six respondents) and the discussion of the translators' activity in social media (three respondents). 


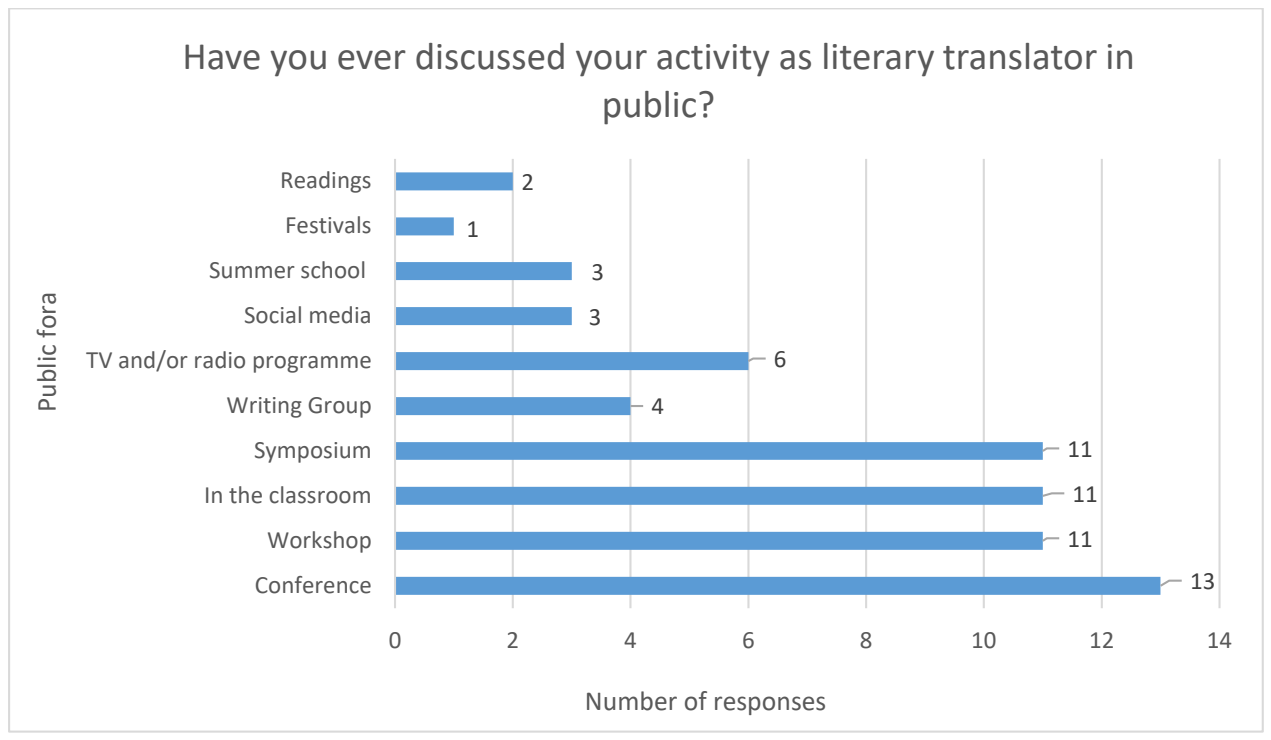

Figure 4. Translation activity discussed in public fora

This data is enriched and expanded by the information in a number of paratexts in which the poetry translators mention their engagement in literary and/or translatorial activities. Hadas (1994) comments on the poetry reading group she was leading at Gay Men's Health Crisis in New York, where she met a number of poets. In her preface to translations of Baudelaire, she recalls Barber, one of the writer's in the group, as "the presiding Muse of these translations" (1994: xv). In a similar vein, in an interview with Paschalis Nikolaou the poet and translator from the Modern Greek Richard Berengarten recalls a number of encounters with literary persons, translators and writers (Berengarten/Nikoloaou 2013); he also discloses how he founded the first Cambridge Poetry Festival in 1975. One of the guest lecturers in that festival was Kimon Friar, a prolific translator from the Modern Greek, met via the Greek poet Katerina Anghelaki-Rooke, who gave a lecture on contemporary Greek poetry (Berengarten/Nikoloaou 2013). This collegial aspect of visibility is also highlighted by Flynn who observes that for the poetry translators who participated in his study "visibility meant recognition by their colleagues, not being mentioned alongside the authors they translate" (2013: 56).

The poetry translators' participation in literary and/or translational activities is also manifest in the interviews:

P8: I belong to a group of translators of poetry from other languages six of us we've worked together for ten years we'd meet once a month and we were all working on different languages and we would try out our translations on each other to see how they worked in English and that was very useful too.

The visibility attested by the translators in the survey, their paratexts and the interviews covers two aspects of translator recognizability, which relate to, firstly, the wider audience and secondly, their peers and the field. This type of visibility allows translators to publicize their translational activities and increase the activity's symbolic value when it is recognized and legitimated by public institutions (such as universities) or the media (TV/radio programmes). At the same time, this visibility may direct the attention of the public to the profession of translator and to the work of specific individuals, which also increases the translator's prestige, and thus symbolic capital, as the translator may be linked to a specific work, author or genre as a consequence.

In summary, the discussion of poetry translators from Modern Greek into English yielded some interesting insights into the formation and usage of their symbolic capital. Poetry translators are active agents with substantial cultural and educational capitals which they use interchangeably as part of their translation activity. The study of their practices and self-description takes us a step 
closer towards the description of the phenomenon of poetry translation while, at the same time, it poses some challenging questions about the boundaries and allegiances of translation as a field of cultural production.

\section{Conclusion}

The aim of this study was to inquire into the symbolic capital of poetry translators from Modern Greek into English through the exploration of three aspects which make up the translators' cultural and educational capital: connection to poetry and to source culture, education, self-description and visibility. The paper presented recent research into the concept of literary translators' symbolic capital and then proceeded to map out the connections between previous research and the information gathered from translators' responses to a survey, from paratexts created (or co-created) by poetry translators from Modern Greek into English and from interviews conducted with some of these translators. In order to operationalize cultural and educational capital the concepts were explored through a number of themes, such as self-description, translation as a secondary activity, the translators' demonstrable love of reading and literature, their engagement with literary activities, their multiculturalism and their connection to the source culture and finally a sense of professional heredity which is passed down the generations.

The responses to the survey, the information from paratexts and from the interviews were explored in the light of these themes in order to identify and describe the embodied and objectified cultural and educational capital of these contemporary poetry translators from Modern Greek into English. Their embodiment of cultural and educational capital is manifest in their love of poetry, high level formal education and training in the Arts. The paratexts and the interviews testify that the role of family and teachers is significant in the inculcation of this embodiment; this inculcation is also manifest in the sense of professional heredity which often characterizes them. Their dedication to the source language and the variety of literary activities they engage with also demonstrate a strong connection to the source culture-often cultivated by living in Greece and learning the language on their own.

This exploration of the cultural and educational capital of poetry translators from Modern Greek into English highlights an aspect of poetic and literary translation also observed by others scholars (Gouanvic 2014, Meylaerts 2013) who both note the problematic of viewing literary translation as an autonomous field of cultural production. The fact that sixteen out of twenty poetry translators are also poets in their own right problematizes their relationship to translation and re-positions them with respect to other translation professionals.

\section{References}

Assinder, Semele 2012: 'To say the same thing in different words': Politics and Poetics in Late Victorian Translation from Modern Greek. In Journal of International Women's Studies, 13(6): 72-84.

Barnstone, Alice 2006: The collected poems of C. P. Cavafy: a new translation. New York: W. W. Norton and Company. Beaugrande, de Robert 1978: Factors in a theory of poetic translating. Assen: Van Gorcum \& Co.

Berengarten, Richard/Nikolaou, Paschalis 2013: Under Greek Light [online]. http://interlitq.org/issue21/paschalis-nikolaou/job1.php (Accessed 15 October 2017).

Bergin, Tara 2013: Ted Hughes and the literal: a study of the relationship between Ted Hughes 's translations of János Pilinszky and his poetic intentions for Crow. Unpublished PhD dissertation. University of Newcastle Upon Tyne.

Blakesley, Jacob 2014: Modern Italian Poets: Translators of the Impossible. Toronto: University of Toronto Press.

Blakesley, Jacob 2016: Examining Modern European Poet-Translators 'Distantly'. In Translation and Literature 25, 10-27.

Blakesley, Jacob 2018: Sociologies of Poetry Translation: Emerging Perspectives. London: Bloomsbury Publishing.

Bourdieu, Pierre 1984: Distinction: A Social Critique of the Judgment of Taste. Cambridge, Massachusetts: Harvard University Press.

Bourdieu, Pierre 1990: The logic of practice. Cambridge: Polity Press. 
Bourdieu, Pierre 1993: The field of cultural production. New York: Columbia University Press.

Bourdieu, Pierre 1997: The forms of capital. In Halsey, A. H./Lauder, Hugh/Brown Philip/Wells Stuart, Amy (eds.), Education: Culture, Economy and Society. Oxford: Oxford University Press, 46-58.

Bullock, Philip Ross 2011: Untranslated and Untranslatable? Pushkin's poetry in English, 1892-1931. In Translation and Literature, 20, 348-372.

Chesterman, Andrew 2009: The name and nature of Translator Studies. In Hermes 42, 13-22.

Chesterman, Andrew 2018: Translation ethics. In D'hulst, Lieven/Gambier, Yves (eds.), A History of Modern Translation Knowledge. Sources, concepts, effects. Amsterdam: John Benjamins Publishing Company, 443-448.

Constantine, David 2011: Service abroad: Hölderlin, Poet-Translator. In Translation and Literature 20, 79-97.

Diaz-Diocaretz, Myriam 1985: Translating poetic discourse: Questions on Feminist strategies in Adrienne Rich. Amsterdam/Philadelphia: John Benjamins Publishing Company.

Dimoula, Kiki 2012: The Brazen Plagiarist: Selected poems. Margellos World Republic of Letters: Yale University Press.

Felstiner, John 1980: Translating Neruda: The way to Macchu Picchu. Redwood City: Stanford University Press.

Flynn, Peter 2005: A linguistic ethnography of literary translation: Irish poems and Dutch-speaking translators. Ghent University. Faculty of Arts and Philosophy, Ghent, Belgium.

Flynn, Peter 2013: How Eurocentric is Europe? Examining scholars' and translators' contributions to translation studies - an ethnographic perspective. In Van Doorslaer, Luc/Flynn, Peter (eds.), Eurocentrism in Translation Studies. Amsterdam/Philadelphia: John Benjamins Publishing Company, 43-59.

Gass, William H. 1999: Reading Rilke: Reflections on the problems of translation. Dublin: Dalkey Archive Press.

Genette, Gerard 1997: Paratexts: Thresholds of interpretation. Cambridge: Cambridge University Press.

Gouadec, Daniel 2010: Translation as a profession. Amsterdam/Phladephia: John Benjamins Publishing Company.

Gouanvic, Jean Marc 2005: A Bourdieusian theory of translation, or the coincidence of practical instances. In The Translator 11, 142-166.

Gouanvic, Jean Marc 2014: Is Habitus as conceived by Pierre Bourdieu Soluble in Translation Studies? In Vorderobermeier, Gisella M. (ed.), Remapping Habitus in Translation Studies. Amsterdam/New York: Brill, Rodopi, 29-42.

Hadas, Rachel 1994: Other words than this: translations. New Brunswick: Rutgers University Press.

Hadas, Rachel 2015: Talking to the dead. New York: Spuyten Duyvil.

Harsent, David 2012: In Secret: Versions of Yannis Ritsos. London: Enitharmon Press.

Heino, Anu 2017: Contemporary Finnish Literary Translators and Symbolic Capital. In Keng, Nicole/Nuopponen, Anita/Rellstab, Daniel (eds.), Ääniä, Röster, Voices, Stimmen. VAKKI-symposiumi XXXVII 9.-10.2.2017. VAKKI Publications 8. Vaasa, 52-63.

Hofstadter, Douglas 1997: Le ton beau de Marot: In praise of the music of language. New York: Hachette Book Group.

Isaxanli, Hamlet 2014: History and Policy of Translating Poetry: Azerbaijan and its neighbors. In Meta: Journal des traducteurs/Meta: Translators'Journal, 59, 310-329.

Jacobs, Adrianna X. 2014: The Go-Betweens: Leah Goldberg, Yehuda Amichai, and the Figure of the Poet-translator. In Bermann, Sandra/Porter, Catherine (eds.), A Companion to Translation Studies. New Jersey: John Wiley \& Sons. Ltd, 479-491.

Jones, Francis 2009: Embassy networks: Translating post-war Bosnian poetry into English. In Milton John/Bandia Paul, Agents of Translation. Amsterdam: John Benjamins Publishing Company, 301-325.

Jones, Francis 2011: Poetry translating as expert action. Amsterdam/Philadelphia: John Benjamins Publishing Company.

Jong de, Engelien 1999: The impact of motivation on the career commitment of Dutch literary translators. In Poetics, 26, 423-437.

Karyotakis, Kostas 2006: Battered Guitars: Poems and Prose. Birmingham: University of Birmingham Press.

Keeley, Edmund 1977: Cavafy's Alexandria: Study of a Myth in Progress. London: The Hogarth Press.

Keeley, Edmund 2000: On translation: Reflections and Conversations. Reading: Harwoord academic publishers.

Kenesei, Andrea 2010: Poetry translation through reception and cognition: the proof of translation is in the reading. Newcastle upon Tyne: Cambridge Scholars Publishing.

Mackridge, Peter 2010: Kay Cicellis: the unresolved dilemma of the bilingual writer. In Wills, David (ed.), Greece and Britain since 1945. Newcastle upon Tyne: Cambridge Scholars Publishing.

Meylaerts, Reine 2010: Habitus and Self-description of Native Literary Authors-Translators in Diglossic Societies. In Translation and Interpreting Studies, 1-19. 
Meylaerts, Reine 2013: The multiple lives of translators. In TTR: traduction, terminologie, rédaction 26, 103-128.

Munday, Jeremy 2014: Using primary sources to produce a microhistory of translation and translators: Theoretical and methodological concerns. In The Translator 20, 64-80.

Munday, Jeremy 2016: Jon Silkin as anthologist, editor and translator. In Translation and Literature, 25, 84-107.

Ober, Kenneth, H./Ober, Warren U. 2004: Puŝkin and Southey: Russia's greatest poet translates England's poet Laureate. In Russian Literature LV, 529-547.

Refsum, Christian 2017: When poets translate poetry: authorship, ownership and translatorship. In Alvstad, Cecilia/ Greenall, Annjo, K./Jansen, Hanne/Taivalkoski-Shilov, Kristiina (eds.), Textual and contextual voices of translation. Amsterdam/New York: John Benjamins Publishing Company, 101-118.

Ruokonen, Mina 2016: Realistic but not pessimistic: Finnish translation students' perceptions of translator status. In The Journal of Specialised Translation 25, 188-212.

Sapiro, Gisele 2013: Translation and identity: Social trajectories of the translators of Hebrew Literature in French. In TTR: traduction, terminologie, redaction 26, 59-82.

Scott, Clive 2012: Translating the Perception of Text. London: Legenda.

Sela-Sheffy, Rakefet 2008: The translator's personae: marketing translatorial images as pursuit of capital. In META LIII 3, 609-622.

Sela-Sheffy, Rakefet 2014: Translators' Identity Work: Introducing Micro-Sociological Theory of Identity to the discussion of translators' habitus. In Vorderobermeier, Gisella M. (ed.) Remapping habitus in Translation Studies. Amsterdam/New York: Rodopi/Brill, 43-55.

Sela-Sheffy, Rakefet 2016: Elite and non-elite translator manpower: The non-professionalized culture in the translation field in Israel. In JoSTrans 25, 54-73.

Simeoni, Daniel 1998: The pivotal status of the translator's habitus. In Target, 10, 1-39.

Skeggs, Beverley 2015: Capital, value and theories of social power. In Holborn, Martin (ed.), Contemporary Sociology. Cambridge: Polity Press, 16-31.

Swartz, David 1997: Culture and Power: the sociology of Pierre Bourdieu. Chicago: University of Chicago Press.

Tall, Emily 1990: Correspondence between three Slavic translators of Ulysses: Maciej Slomczynski, Aloys Skoumal and Viktor Khinkis. In Slavic Review 49, 625-633.

Trypanis, Costantine 1971: The Penguin Book of Greek Verse. London: Penguin Books.

Vardoulakis, Dimitris 2001: An interview with Edmund Keeley. In Colloquy, 5, Monash Arts, [online]. http://artsonline. monash.edu.au/wp-content/arts-files/colloquy/colloquy_issue_five_vardoulakis.pdf (Accessed 12 October 2017).

Voinova, Tanya/Shlesinger, Miriam 2013: Translators talk about themselves, their work and their profession: the habitus of translators of Russian literature into Hebrew. In TTR: traduction, terminologie, rédaction, 26, 29-57.

Vorderobermeier, Gisella 2014: The (Re-)Construction of Habitus: A survey-based account of literary translators' trajectories put into methodological perspective. In Vorderobermeier, Gisella M. (ed.), Remapping habitus in Translation Studies. Amsterdam/New York: Rodopi/Brill, 149-161.

Waldinger, Albert 2003: Stopping by the woods: Classic American poems in Yiddish. In TTR: traduction, terminologie, rédaction, 16, 155-174.

Wang, John C. 1965: Ezra Pound as a Translator of Classical Chinese Poetry. In The Sewanee Review, 73(3), 345-357.

Weissbort, Daniel 1989: Translating Poetry: The double labyrinth. Basingstoke: Palgrave Macmillan.

Weissbort, Daniel/ Eysteinsson, Ástrádur 2006: Translation : Theory and practice : A historical reader. Oxford: Oxford University Press.

Wolf, Michaela 2013: "Prompt, at any time of the day...": the emerging translatorial habitus in the late Habsburg monarchy. In Meta: Journal des traducteurs/Meta: Translators' Journal 58(3), 504-521.

Wright, Chantal 2016: Literary Translation. New York: Routledge. 